\title{
Aproximación al uso del modo subjuntivo en el Corpus sociolingüístico de la ciudad de México
}

\author{
Yolanda Lastra \\ Universidad Nacional Autónoma de México y El Colegio de México \\ Pedro Martín Butragueño* \\ El Colegio de México
}

\begin{abstract}
Resumen
El principal objetivo de este artículo es estudiar la vitalidad del subjuntivo en la lengua hablada de la ciudad de México y detectar las alternancias motivadoras de variación con el indicativo. Para ello, se consideran 1164 muestras de subjuntivos procedentes de 18 informantes del Corpus sociolingüístico de la ciudad de México. Como variables lingüísticas, se analiza el tiempo verbal, la literalidad de la construcción, la modalidad del enunciado, el contexto sintáctico, los valores semántico-pragmáticos, así como la polaridad, la factualidad, la probabilidad, la asertividad y la intercambiabilidad con el indicativo. Las variables sociolingüísticas son la procedencia del dato, el nivel de estudios, la edad y el género. El estudio reafirma la plena vitalidad del subjuntivo (especialmente en las personas con más estudios, los jóvenes y las mujeres). Los
\end{abstract}

* Para correspondencia dirigirse a: Yolanda Lastra (ylastra@servidor.unam.mx) o Pedro Martín Butragueño (pmartin@colmex.mx), Universidad Nacional Autónoma de México, Instituto de Investigaciones Antropológicas, Ciudad Universitaria, 04510 México, D.F. México y El Colegio de México, Camino al Ajusco 20, Col. Pedregal de Santa Teresa, México, D.F. 10740, México. 
tiempos verbales subjuntivos más comunes son el presente y el pretérito. Los contextos sintácticos y los valores semánticos y enunciativos son importantes para caracterizar el uso del subjuntivo, pero para expresar la alternancia con el indicativo debe considerarse la factualidad, la probabilidad y la asertividad implicadas en cada ejemplo específico. Deberá profundizarse en especial en los 439 casos con cierta intercambiabilidad con el indicativo.

Palabras clave: uso del subjuntivo, español de la ciudad de México, variación sintáctica.

\title{
AN APPROXIMATION TO THE USE OF THE SUBJUNCTIVE MOOD IN THE Sociolinguistic CoRpus of MEXICO City
}

\begin{abstract}
The main goal of this paper is to study the vitality of the subjunctive in theSpanish speech of Mexico City and find alternations with the indicative. To this purpose 1164 samples of subjunctive forms in 18 speakers from the Sociolinguistic Corpus of Mexico City were examined. As linguistic variables, tense, the conventionality of the construction, the form of the utterance, its syntactic context, and main semantic-pragmatic values were analyzed; polarity, factuality, probability, assertiveness and interchangeability with the indicative were also taken into account. The sociolinguistic variables considered were level of education, age, and gender. The study reaffirms the full vitality of the subjunctive (especially in people with more education, youth and women). The most common subjunctive tenses are the present and the past. Syntactic contexts and semantic and pragmatic values are important to characterize the use of the subjunctive, but in order to understand the alternation with the indicative, it is necessary to consider the factuality, probability and assertiveness involved in each specific instance. More detailed study of the 439 cases of relative interchangeability with the indicative could be carried out.
\end{abstract}

Key words: use of subjunctive, Spanish of Mexico City, syntactic variation.

Recibido: 02/07/2012 Aceptado: 28/11/2012 
En el marco de una serie de trabajos dedicada al estudio de las formas verbales en el Corpus sociolingüistico de la ciudad de México (cf. Lastra y Martín 2010), se plantea ahora una aproximación al estudio de los valores de las formas del modo subjuntivo documentables en el Corpus, prestando atención a una muestra de 18 informantes, distribuidos en tres grupos de estudios, tres de edad y hombres y mujeres ${ }^{1}$. En especial, se pretende prestar atención a dos hechos generales: $a$ ) la vitalidad del empleo de las formas de subjuntivo en la ciudad de México, que puede llevar a la comparación con otras variedades de habla ( $c f$. Silva Corvalán 1994, 2001; Studerus 1995; Knauer 1998); b) la detección de alternancias motivadoras de variación, en especial entre indicativo y subjuntivo (del tipo creo que puedo vs. creo que pueda), allí donde se producen contextos intercambiables, aunque visto el problema ahora solo desde el ángulo del subjuntivo ${ }^{2}$.

La selección modal es compleja y obedece a una amplia serie de factores, de corte sintáctico, semántico, pragmático y variable (véase para un panorama el cap. 25 de la NGRAE 2009: 1865-1960 y Bosque 1990). Existe una larga tradición gramatical en la que se ha discutido la fundamentación de la alternancia modal. El subjuntivo es, en principio, un modo asociado a las oraciones subordinadas, sean nominales, relativas o adverbiales. Para Bello, por ejemplo, piden subjuntivo las subordinaciones que denotan incertidumbre, duda o una emoción del ánimo (1981:330). Uno de los problemas más clásicos en la gramática del español es la búsqueda de un valor unitario para el subjuntivo. Se ha descrito como el modo de la no-realidad, la incertidumbre, la subjetividad, la virtualidad, la futuridad indefinida (cf. el resumen de Busch 2009: 147-148). No faltan tampoco elementos pragmáticos que influyan en la elección del subjuntivo; uno de ellos es la atenuación. Considérese el ejemplo (1):

(1)I: ¿que lo necesité?/ a la mejor y sí/ para algún consejo de $<\sim$ de: $>/$ de algo/ ¿no?/ o sea no es lo mismo que tengas a tu tío de/ no sé o de papá/ que te ¡dé una imagen!/ a que tengas realmente a tu papá/ ¿no?/ que ya $<\mathrm{le}>/$ pedirías un con-/ un consejo de algo/ o sea de/ "¿cómo crees que le pueda hacer para/ este chavo?"/ o equis/ ¿no? (risa) (entrevista 84, ME-307-11M-07, turno 487)

\footnotetext{
Una versión preliminar (no entregada para publicación en las correspondientes Actas) se leyó en el XVI Congreso Internacional de ALFAL, celebrado en Alcalá de Henares (Universidad de Alcalá, 6-9 de junio de 2011).

2 También podrían haberse considerado casos de indicativo por subjuntivo, como señala DeMello (1996) para las cláusulas regidas por expresiones de reacción personal, como en $\mathrm{Me}$ repugna asi francamente que la gente es mal agradecida (p. 367).
} 
El valor de atenuación, implícito en el mayor alejamiento con respecto a la factualidad de la acción, parece ser aprovechado mediante el empleo de pueda, frente a los posibles puedo, podré, podría; obsérvese la concurrencia de otros elementos con posible valor atenuador, como el creer introductor, el le intensivo y la propia ausencia del elemento verbal (digamos conseguir) que encabeza la oración término de la preposición para, que provoca la vinculación más pragmática que sintáctica de este chavo, expresada por la cesura entonativa. El caso del verbo creer es particularmente interesante, pues en forma afirmativa pediría indicativo (aunque no siempre es así, como puede verse en el ejemplo 1), mientras que en forma negativa permite la alternancia modal (Yolanda no cree que su perra es latosa / Yolanda no cree que su perra sea latosa), pero de manera que el indicativo compromete al hablante con la verdad del enunciado y el subjuntivo no (Ridruejo 1999, Rivero 1990). Tales contextos negativos manifiestan diferencias propiamente semánticas entre los modos (García Fajardo 2001: 97).

Además, el uso del subjuntivo ha motivado diversos trabajos de corte sociolingüístico, o por lo menos, de lenguaje visto en contexto, desde los análisis pioneros de Lavandera (1984) a una larga serie de trabajos posteriores (véase, por ejemplo, la síntesis incluida en Blas Arroyo 2005: 100-110).Desde un punto de vista variacionista, es necesario tener en cuenta que cabe distinguir tres situaciones posibles: a) casos en que la conmutación modal es posible, pero se introduce una diferencia de significado según cuál sea la selección; b) situaciones de libre alternancia en que el cambio no indica, en principio, modificación del valor gramatical; c) contextos de sustitución imposible, como ocurre en los casos específicos de rección de un modo (Veiga 2006: 97).

Cada uno de los tiempos de subjuntivo requeriría, por otra parte, un análisis específico. Para García Fajardo, "muchos de los valores que se le han querido adjudicar al pretérito de subjuntivo surgen del resultado composicional de éste con el contenido de otros predicados" (2001, p. 99), de modo que es la oración subordinante la que permite presentar la subordinada como presupuesta, contrafáctica o hipotética (deseo, duda, etc.). En el pretérito de subjuntivo, se mantiene la suspensión de la aserción y queda a disposición referencial de la influencia de la oración principal. La no aserción se mantiene tanto en los contextos de libre selección como en los contextos que rigen subjuntivo (ibíd., p. 100); es lo que explica el descompromiso con la verdad del material subordinado a creer negado (María no cree que el niño comiera la sopa) (p. 101) .

\footnotetext{
3 El pretérito aportaría, de todos modos, un tipo de modalidad, concebido como un operador que desconecta la proposición del mundo real, permitiendo expresar la planeación
} 
Quizás, una de las propuestas más atractivas sea la desarrollada por Veiga en varios trabajos (véase, en especial, 2006, así como los comentarios de Vázquez Laslop 2007: 11-14). Existirían tres oposiciones modales básicas: i) objetivo / subjetivo (manifestable como indicativo frente a subjuntivo); ii) irrealidad / no irrealidad; y iii) incertidumbre / no incertidumbre (aplicado este último solo a los casos de no irrealidad). La inmensa mayoría de los casos considerados en este trabajo son ejemplos subjetivos (aunque hay algunos casos objetivos; ante todo, de formas en -ra); la irrealidad y la incertidumbre se han considerado también, pero dentro de un marco más descriptivo que estructural.

\section{ANÁLISIS DE RESULTADOS}

El primer comentario general que es necesario hacer es subrayar la vitalidad del modo subjuntivo en los materiales orales de la ciudad de México, frente a lo que a veces pudiera pensarse. En las 18 horas de otras tantas entrevistas que hemos considerado, ha surgido un total de 1164 casos, referidos a distintos tiempos verbales, anclados en diferentes contextos sintácticos y dotados de valores semánticos muy variados. Se consideran, en primer término, los factores lingüísticos involucrados en la distribución de las formas subjuntivas $\mathrm{y}$, en segundo término, los factores sociales considerados.

\section{FACTORES LINGÜÍSTICOS}

El cuadro 1 muestra la distribución de las formas documentadas de subjuntivo según los tiempos verbales; como puede apreciarse, hubo una mayoría de formas en presente (más o menos 2 de cada 3 casos), seguidas por las formas en pretérito ( 1 de cada 4 casos, aproximadamente). Y aunque las cantidades de antepresente y antepretérito no son muy elevadas, muestran, de todas

\footnotetext{
y estructuración de cosas no presentes y no asegurables en el futuro. De hecho, sus valores se bifurcan en dos tipos de modalidad (como expresión lingüística de la subjetividad): así, con creer negado, la suspensión de la aserción mueve la responsabilidad del acto de habla (El policía no cree que el ladrón entrara por la ventana); subordinado el pretérito a verba dicendi o a verbos evidenciales, el sujeto de la subordinante adquiere mayor involucramiento (ibíd., pp. 105-111 e infra).
} 
formas, una presencia nada despreciable. No hubo, como era de esperarse, ninguna documentación de futuro o de antefuturo.

Cuadro 1. Distribución de los tiempos verbales. N=1164

\begin{tabular}{|l|r|c|}
\hline & \multicolumn{1}{|c|}{ F } & f \\
\hline Presente & 783 & 0.673 \\
\hline Pretérito & 277 & 0.238 \\
\hline Antepresente & 35 & 0.030 \\
\hline Antepretérito & 69 & 0.059 \\
\hline
\end{tabular}

En (2), se muestran algunos ejemplos de cada uno de los tiempos verbales de subjuntivo.

a. es un proyecto donde se se dice que o se se quiere hacer que/ las azoteas de la ciudad de México se conviertan en jardines (presente; entrevista 50; 22H; turno 456).

b. yo me fui a trabajar/// y pasaron este// los días/ y yo sentía como que no/ yo dije/ "ah pero pu-/ ¿por qué se me ve el hueso como si lo tuviera salido? a lo mejor/ lo tenía hinchado"/ y yo dije/ "a lo mejor ya se me baja lo hinchado y ya se me va a quitar"/ pero no (pretérito; entrevista 60;22M; turno 473).

c. la apariencia ha de condicionar la identidad que tienes/ ¿no?/ aunque hayas vivido siempre en México (antepresente; entrevista 48; 21M; turno 404).

d. pues $<\sim$ pus $>$ ya le dije que era gay $<\sim$ gue:y $>/$ y mi mamá pues $<\sim$ pus $>$ / fíjate/ nunca me hubiera esperado una/ reacción así de mi mamá/ me dijo/ "mira/ no sé qué contestarte// dame tiempo/y después hablo contigo" (antepretérito; entrevista 42; $21 \mathrm{H}$; turno 186).

No hubo ningún caso de pretérito que empleara la forma en $-s e^{4}$. De entre los 69 antepretéritos, solo en dos ocasiones se empleó la forma con hubiese, ambos en boca del mismo informante:

\footnotetext{
$4 \quad$ El hecho es también interesante no solo por las dimensiones dialectales, sino por la repercusión funcional, pues como observa García Fajardo (2001: 95, n. 2), la invasión del campo propio del pospretérito efectuada por las formas en - $r a$ no tiene lugar con las formas en -se. La restricción no parece válida para el antepretérito, a juzgar por los ejemplos que
} 
(3)

a. cuando me cambié allá/ allá por este// ¿cómo se llama?// bueno/ ahí ya tiene// mucho tiempo que// me quedé// pero me hubiese que-/ mira yo me que-/ más bien/ me quería cambiar// pero mis papás tuvie-/ no tuvieron ya la oportunidad/ y ahí nos tuvimos que quedar (antepretérito con hubiese; entrevista 6; 31H; turno 26).

b. por suerte el ingeniero no se dio cuenta de esa puerta/ si no [...] [me] hubiese regañado (antepretérito con hubiese; entrevista 6; 31H; turno 325).

Resulta interesante comparar nuestros resultados generales con los presentados en Moreno de Alba (2003a), quien parte del examen de 10 horas de grabación de 22 informantes recogidos en el marco del proyecto para el estudio de la norma culta (p. 26).

Cuadro 2. Comparación de los resultados actuales con los de Moreno de Alba (2003a)

\begin{tabular}{|l|r|r|r|r|}
\hline & \multicolumn{2}{|c|}{ Este trabajo } & \multicolumn{2}{c|}{ Moreno de Alba (2003a, p. 33) } \\
\hline Presente & 783 & 0.673 & 666 & 0.784 \\
\hline Pretérito & 277 & 0.238 & 126 & 0.148 \\
\hline Antepresente & 35 & 0.030 & 16 & 0.019 \\
\hline Antepretérito & 69 & 0.059 & 41 & 0.048 \\
\hline Futuro & 0 & 0.000 & 1 & 0.001 \\
\hline Antefuturo & 0 & 0.000 & 0 & 0.000 \\
\hline Totales & 1164 & 1.000 & 850 & 1.000 \\
\hline
\end{tabular}

Moreno de Alba documentó una cantidad relativamente mayor de formas subjuntivas en las 10 horas de norma culta que nosotros en los materiales de tres grupos sociales, pues, guardando las mismas proporciones, deberíamos haber obtenido unos 1530 casos (en vez de 1164), o bien debería haber unos 647 ejemplos en las grabaciones cultas (cuando en realidad hubo 850).

anotamos en (3), especialmente en (3b), donde aparece la forma completa, pues en el mismo contexto parece caber hubiese regañado, hubiera regañado y habría regañado. Además, y como recuerda Vázquez Laslop, diferentes autores "han detectado casos de amase con valor indicativo, permutable con amaría" (2007: 11, n. 31), incluidos de pudiese en vez de pudiera (cf. la bibliografía allí citada), como en Digo que, un hermano de él pudiese ser el presidente (ibíd., ejemplo 17b, p. 17). 
Aunque puede pensarse que esto es lo esperado, el examen de la distribución de los tiempos particulares muestra algunas sorpresas. En los materiales de Moreno, el predominio de las formas en presente fue mayor que en la colecta actual, y al tiempo se documentó una proporción menor de pretéritos $(0.148$ antes y 0.238 ahora), antepresentes $(0.019$ frente a 0.030$)$ y antepretéritos (solo 0.048 en el primer muestreo por 0.059 en los datos actuales). Quizás, la reflexión que cabe hacer es que el grado relativo de informalidad presente en las entrevistas del Corpus sociolingüistico de la ciudad de México permite la aparición de fragmentos de muy variadas características discursivas, lo cual podría haber propiciado esta mayor diversificación.

Una acotación que nos ha parecido importante es lo que hemos llamado literalidad de la construcción (recordando, en parte, la propuesta de Lázaro Carreter 1981), de forma tal que se considere aquellas construcciones donde se espera un infinitivo debido a cierto grado de fijación de la expresión, sea que se trate de giros discursivos - destinados, por ejemplo, al mantenimiento del turno de habla- o de frases fijas que tienden a ritualizar algunos fragmentos de la conversación. Estas expresiones literales suman casi un $10 \%$ del total de los datos (véase el cuadro 3); por lo tanto, pueden suponer un condicionamiento llamativo para la aparición de los subjuntivos.

\section{Cuadro 3. Literalidad de la construcción}

\begin{tabular}{|l|c|c|}
\hline & F & f \\
\hline No literal & 1054 & 0.905 \\
\hline Literal & 110 & 0.095 \\
\hline
\end{tabular}

Los casos incluidos en (4a) presentan tres de entre los muchos usos no literales del subjuntivo; en contraste, (4b) muestra el giro ¿Cómo te dijera?, bastante común en la muestra y destinado en apariencia a ganar el tiempo necesario para no perder el turno de habla. Obsérvese que la expresión es preferida a la posible ¿Cómo te diría?, de modo que no se trata de un condicionamiento sintáctico, sino de una preferencia de orden discursivo ${ }^{5}$. El ejemplo (4c) expone una de las fórmulas ritualizadas que llevan subjuntivo

\footnotetext{
5 Aunque puede asociarse con el conocido problema de la alternancia de pretérito de subjuntivo con pospretérito de indicativo, no parece obvio que el pretérito pierda en este caso su carácter modal subjetivo; además, parece incluir una negación implícita, lo que lo acerca a sentidos de carácter irreal. Vistas así las cosas, parece otro ejemplo de forma subjuntiva en oración independiente, sumida en un enunciado interrogativo interaccional (en términos de Escandell 1993), pero poco verosímil en forma declarativa: Te diría que es tarde, ${ }^{*}$ Te dijera que es tarde. Quizá convendría explorar el papel de decir como verbo performativo (cf. Yule
} 
habitualmente, que Dios los bendiga; considérese que este tipo de fórmulas pueden aparecer como principales, más allá de que pueda suponerse un marco performativo volitivo: ('quiero, pido que') Dios te bendiga. Por fin, (4d) exhibe un ejemplo de o lo que sea, cuya función discursiva es concluir una enumeración; finalidad parecida tienen formas como o lo que quieras, $o$ donde quieras y otras expresiones bastante comunes en el corpus.

a. o luego ve por ejemplo una chamaquita de la secundaria con novio ¿no?/ así abrazándose y besándose "nada más que te vea yo así me las vas a pagar" dice "ay papá como si ya me estuvieras viendo/ te digo mamá ve a mi papá"/ le digo "ay no le hagas caso" (lenguaje no literal; entrevista 96; 12M; turno 555).

b. yo creo que si me de-/ siguiera $<a>$ los camiones no// pues no no este/ ¿cómo te dijera?/ esclavizas mucho tu tiempo/ ¿no? (lenguaje literal; entrevista 50; 22H; turno 137).

c. ya sus viáticos ya no les alcanzaban/ entonces $<\sim$ entós $>/$ todo eso también me lo < lo: $>/ /$ lo valoraban aunque $<\sim$ anque $>/$ llegaba yo diciendo/ "carajo tú/ con el puro pasajito se llevan el puro metro (risa)/ ya ni la amuelan" [...] mm/ pues $<\sim$ ps:: $>/$ por ejemplo/ ya les daba la salida a Querétaro/ "órale/ y ya de aquí que Dios los bendiga"/ y ya me venía yo en el metro [...] pero ya me venía directamente a la casa $[. .$.$] o sea/ estaba bonito el$ trabajo (lenguaje literal; entrevista 66; $23 \mathrm{H}$; turno 684).

d. eso es lo que hacía uno/ entonces < tons $>$ lo que ganaba uno pues $<\sim$ pus $>$ a veces/ pues < pus $>$ haciendo mandados o/ o tirando basuras o lo que sea (lenguaje literal; entrevista 102; 13H; turno $80)$.

Nos ha parecido interesante considerar el tipo de modalidad enunciativa en que se inserta la forma de subjuntivo ${ }^{6}$. Tal como muestra el cuadro 4, la inmensa mayoría de los ejemplos aparece en enunciados aseverativos (casi

2011: 49-50), pero ello requeriría, desde luego, un estudio puntual que no podemos abordar aquí.

${ }^{6}$ En el sentido del enunciado completo en el que aparecen. En otro sentido, se ha propuesto que las formas indicativas son declarativas y las de subjuntivo no, dado que las primeras pueden ser núcleo de oración independiente (García Fajardo 2001: 98-99); la excepción en pretérito es querer, que admite construcciones como Quisiera escuchar a Jordi Savall en Bellas Artes, invadiendo el campo del pospretérito (ibíd., p. 102). Esta es cuestión 
9 de cada 10 ejemplos, como en 5a). Hay, sin embargo, un cierto número de enunciados interrogativos que de modo habitual se inserta en forma de estilo indirecto, aunque a veces aparece en forma directa, precisamente como ocurre en (5b). En especial, interesantes son los casos que hemos etiquetado como modalidad imperativa, pues se trata de subjuntivos en ámbitos negativos que corresponderían a formas imperativas en caso de ser afirmativas; así, en el ejemplo (5c), no te la lleves, correspondería a llévatela. Otro tanto ocurre en fórmulas parcialmente ritualizadas, también muy comunes en los materiales recogidos, como no te preocupes, que en un enunciado afirmativo correspondería a preocúpate. Este tipo de casos habla del problema clásico de los límites entre el modo subjuntivo y el modo imperativo. Por último, el ejemplo (5d) recoge el único caso etiquetado como exclamativo, donde por cierto qué bueno que le den por lo menos esa oportunidad podría intercambiarse por qué bueno que le dan por lo menos esa oportunidad, simplemente con aumentar la asertividad de la expresión, como se comentará más adelante.

Cuadro 4. Distribución de la modalidad enunciativa

\begin{tabular}{|l|r|c|}
\hline & \multicolumn{1}{|c|}{ F } & f \\
\hline Aseverativa & 1021 & 0.877 \\
\hline Interrogativa & 75 & 0.064 \\
\hline Imperativa & 67 & 0.058 \\
\hline Exclamativa & 1 & 0.001 \\
\hline
\end{tabular}

a. Actipan [...] era bien bonito porque/ bueno/ como que vivías en un pueblo// no había/ pavimento/ no había/ a lo mejor ni luz/ yo no me acuerdo que hubiera luz// digo en la calle/ ¿no?// había unos arbolotes gigantescos/ que nada más queda como uno o dos ahí en/ en el barrio (aseverativa; entrevista 50; 22H; turno 209).

b. quitaron todos los puestos/ todos los jacales llegó el departamento central con carros/para < pa $>$ arriba y y se llevaron/lo dejaron a uno ahí (risa) en [la calle] [...] sí ahí lo dejaron ahí a uno/ te decían "no pues < pus> que/ que ia dónde quieres que te llevemos (sic)?" (interrogativa; entrevista 102; 13H; turno 269).

que se ha planteado tradicionalmente, aduciendo diferentes casos, más o menos discutibles, con subjuntivo independiente: Ojalá venga, Mejor callara. 
c. no puedes competir tú como médico con la muerte y/ "no te la lleves/y espérame y..."/ no// digo/ tú haces todo lo posible/ bueno más bien/ he visto que hacen todo lo posible// y pues < pus $>$ ya/ no se pudo y/ pues < pus $>$ ni modo/ no se pudo (imperativa; entrevista $12 ; 31 \mathrm{M}$; turno 165 ).

d. qué bien// [qué bueno] [...] que le den por lo menos esa oportunidad a sus hijos (exclamativa; entrevista 50; entrevistador; turno 582).

Varios de los factores lingüísticos que se mencionan a continuación se han adaptado a partir del trabajo que Silva-Corvalán (1994) dedicó a la pérdida gradual de las distinciones de modo en el español de Los Ángeles ${ }^{7}$-envuelto en una situación de bilingüismo-, aunque ciertamente nuestros resultados no apuntan para nada a la pérdida de tales distinciones, debido sin duda a las muy diferentes circunstancias sociolingüísticas ${ }^{8}$.

El cuadro 5 clasifica los contextos sintácticos básicos; se han separado las prótasis y las apódosis de las oraciones condicionales, que podrían haberse sumado, respectivamente, a las subordinadas adverbiales y a las oraciones principales ${ }^{9}$.

7 De hecho, en buena medida la motivación inicial de este artículo era la de disponer de una base de comparación con datos mexicanos actuales de la ciudad de México, de modo que la organización de los datos en Silva-Corvalán (1994) ha sido en todo momento un referente a la hora de organizar nuestros materiales, aunque en algunos casos hemos considerado necesario apartarnos a la hora de conformar las variables lingüísticas y sociolingüísticas.

8 Estamos de acuerdo con Martin Hummel cuando señala que "las hipótesis de decadencia del subjuntivo tienen poco fundamento. Queda claro, sin embargo, que [diacrónicamente] hubo ascensión del subjuntivo en la tradición escrita [...]. En el habla popular, la oposición indicativo / subjuntivo es plenamente activa. Sin embargo, hay que matizar este cuadro general, cuando se consideran las funciones concretas" (c. p., carta del 15 de junio de 2011; cf. sus trabajos de 2004 y 2005).

$9 \quad$ En el trabajo de Silva-Corvalán (1994) se considera de manera conjunta los contextos sintáctico-semánticos, distinguiendo entre los siguientes: construcciones causativas; volitivas; proposiciones de propósito; proposiciones concesivas; comentario; modales (proposición principal); acto mental; proposición temporal; apódosis; prótasis; incertidumbre; proposición de modo; proposición locativa; proposición adjetiva; asertivas; otras. Más allá de algunas diferencias de relativo detalle en nuestra clasificación, hemos preferido separar los aspectos sintácticos de los semánticos por considerar que, aunque existe una tendencia a que ciertos contextos sintácticos estén vinculados con ciertos valores semánticos y viceversa, esta relación no es completamente estable ni biunívoca. 
Cuadro 5. Distribución de los contextos sintácticos básicos. N=1164

\begin{tabular}{|l|r|c|}
\hline & $\mathrm{F}$ & $\mathrm{f}$ \\
\hline Subordinada sustantiva & 472 & 0.405 \\
\hline Subordinada relativa & 176 & 0.148 \\
\hline Subordinada adverbial & 324 & 0.278 \\
\hline Prótasis de condicional & 39 & 0.034 \\
\hline Apódosis de condicional & 27 & 0.023 \\
\hline Coordinada & 11 & 0.009 \\
\hline Oración principal & 115 & 0.099 \\
\hline
\end{tabular}

El contexto más frecuente de aparición de las formas subjuntivas son las oraciones subordinadas sustantivas (más o menos en 4 de cada 10 casos), cuyos valores semántico-pragmáticos principales fueron expresar la existencia, la evaluación, la creencia, la volición, la incertidumbre y la causación; el ejemplo (6a) muestra una subordinada sustantiva volitiva, introducida por el verbo querer. Mucho menos frecuentes fueron las subordinadas relativas (son aproximadamente el 15\% del total de los datos; puede verse uno de los ejemplos en (6b). La mayor parte de las relativas presentó valores existenciales y volitivos. Cabe destacar la recurrencia de expresiones literales del tipo o lo que sea, o lo que quieras y otras por el estilo, ya mencionadas. Las subordinas adverbiales - que corresponden más o menos a 1 de cada 4 casos- se presentaron bastante repartidas en los diferentes subtipos sintáctico-semánticos, pero llama la atención la abundancia de finales, temporales y concesivas; el ejemplo (6c) exhibe precisamente uno de los casos de subordinada adverbial final. Casi todos los datos de prótasis condicionales tienen sentido hipotético (cuando son afirmativas) o de incertidumbre (cuando se encuentran en el marco de un ámbito negativo); los dos casos incluidos en el ejemplo (6d) son de prótasis hipotéticas: si me hubiera yo esperado, si yo le hubiera buscado la manera. Por su parte, la inmensa mayoría de las apódosis de condicionales se desenvuelven como hipotéticas, tal como se muestra en los tres datos del ejemplo (6e). Como quedó anotado en el cuadro 5, hubo unos pocos ejemplos en los cuales la proposición que incluye el subjuntivo aparece coordinada. Los valores están muy repartidos, y solo las adversativas muestran una cierta recurrencia; el ejemplo (6f) es precisamente un caso de coordinada adversativa. Por último, en un $10 \%$ de las ocasiones el subjuntivo aparece inscrito en una cláusula principal. El valor más común de estas proposiciones es el volitivo, aunque hay que aclarar que hemos etiquetado como volitivos el uso del subjuntivo como imperativo negativo, en la medida en que se trata de una orden o una recomendación, como se muestra en el ejemplo (6h). El resto de los valores de 
las principales aparece muy repartido: modales, existenciales, desiderativas (como en el ejemplo 6g), etc.

a. "mi hermano el< el: $>$ / J es el que me dice/ "métete a tra-/ a estudiar porque no te quiero ver todo el tiempo trabajando de limpieza"/ dice/ "yo ya lo pasé/ pero tú no/ yo no quiero que tú pases esto" (subordinada sustantiva; entrevista $84 ; 11 \mathrm{M}$; turno 938).

b. dice "debes de ser una/ una niña normal/y este/ tú vas a tener una edad en que ya te puedas pintar y todo" (subordinada relativa; entrevista 96; 12M; turno 559).

c. mi mamá no me quería dar el acta para que no me fuera a casar (subordinada adverbial; entrevista 96; 12M; turno 251).

d. o sea me reconocieron nada < na> más < más:: $>$ diecisiete/ porque $<\sim$ porque: $>$ eh/ por eso es lo que/ $\mathrm{y}<\sim \mathrm{y}$ : $>$ si me hubiera yo < yo:>esperado [...] los cuatro años/ me hubieran este/ evaluado los demás [...] si yo le hubiera buscado la manera/ y entonces mi pensión no estuviera tan raquítica [...] hubiera sido jubilación completa/ a los treinta años (prótasis de condicional; entrevista $66 ; 23 \mathrm{H}$; turno 342 ).

e. o sea me reconocieron nada < na $>$ más < más:: $>$ diecisiete/ porque $<\sim$ porque: $>$ eh/ por eso es lo que/ y $<\sim$ y: $>$ si me hubiera yo < yo:> esperado [...] los cuatro años/ me hubieran este/ evaluado los demás [...] si yo le hubiera buscado la manera/ y entonces mi pensión no estuviera tan raquítica [...] hubiera sido jubilación completa/ a los treinta años (apódosis de condicional; entrevista $66 ; 23 \mathrm{H}$; turno 342 ).

f. pues <pus> sí ya saben a lo que vienen/ y que esto y que lo otro (risa) cuántos son (risa)/ o sea sí/ pues < pus> sí estabamos preparados pero ya [...] el otro s-/ el último fue en particular/ pero bendito sea Dios (coordinada; entrevista 66; $23 \mathrm{H}$; turno 556).

g. ojalá nos tocara (oración principal; entrevista 50; otro participante; turno 489).

h. pero dice "no mamá/// no no te preocupes/ porque/ pues las cosas pasan/y ni modo" (oración principal; entrevista 108; 13M; turno 39).

A continuación se repasan los principales valores semántico-pragmáticos expresados por medio de los subjuntivos recolectados (cuadro 6). 
Cuadro 6. Distribución de los valores semántico-pragmáticos principales.

$\mathrm{N}=1164$

\begin{tabular}{|l|c|c|l|c|c|}
\hline & $\mathrm{F}$ & $\mathrm{f}$ & & $\mathrm{F}$ & $\mathrm{f}$ \\
\hline causa & 25 & 0.021 & hipótesis & 85 & 0.073 \\
\hline causación & 12 & 0.010 & incertidumbre & 26 & 0.022 \\
\hline comparación & 24 & 0.021 & locación & 23 & 0.020 \\
\hline concesión & 47 & 0.040 & modalidad & 16 & 0.014 \\
\hline consecución & 11 & 0.009 & modo & 30 & 0.026 \\
\hline creencia & 38 & 0.033 & tiempo & 68 & 0.058 \\
\hline evaluación & 48 & 0.041 & volición & 214 & 0.184 \\
\hline existencia & 364 & 0.313 & otros & 26 & 0.022 \\
\hline fin & 107 & 0.092 & & & \\
\hline
\end{tabular}

El valor documentado en más ocasiones es el existencial, en algo más del $30 \%$ de las ocasiones; con este valor hemos querido señalar los casos en que predomina el valor referencial y se subrayan las condiciones de existencia del evento desarrollado en la proposición en la que se instala el subjuntivo; copiamos en (7h) uno de los muchos ejemplos con este valor. El segundo sentido más común es el volitivo, sentido asociado claramente a la selección de subjuntivo. Es necesario aclarar que aquí se han reunido sobre todo dos dimensiones no necesariamente equivalentes: por un lado, los subjuntivos incrustados en subordinadas sustantivas introducidas por el verbo querer y otros afines y, por otro lado, los subjuntivos con valor imperativo negativo, atendiendo a su función apelativa. Ejemplos como (7p), del tipo no quiero que te juntes, sugieren, de todas formas, una relativa comunicabilidad entre ambos subvalores. Las expresiones con valor final -en principio, casos de subordinas adverbiales- son también bastante frecuentes en el corpus, como se muestra en (7i); normalmente rigen subjuntivo de manera obligatoria. El cuarto valor más común es el hipotético, en la mayoría de los casos asociado, como se ha dicho, a las prótasis (ejemplo 7j) y apódosis condicionales.

Un segundo bloque de valores aparece también notoriamente, pero con frecuencias menores a las anteriores. Se trata de los sentidos temporal (ejemplo 7o), evaluativo (7g), concesivo (7d), de creencia (7f) y de modo (7n). Se anotan también ejemplos del resto de valores menos documentados.

a. no es porque sea mi hija/ cuando están las presentaciones/ a lo mejor le falta un poco de gracia/ porque es así como// secona/ ¿no?/ pero/ les dan las indicaciones/ y ella lo hace/ y hay otras niñas que se equivocan (causa; entrevista 23; 32M; turno 517). 
b. pero antes de que naciera el niño yo/ me puse a trabajar en una casa/ en una casa me puse a trabajar/de sirvienta/ y ahí me trataba muy mal la señora/ me su-/ me hacía quesubierayo botes de agua/ para arriba de la/ del segundo piso/ porque no había agua/ arriba/ y me hacía que subiera/ así embarazada/ tenía yo que subir botes de agua/ para hacer el quehacer de arriba (causación; entrevista 108; 13M; turno 23).

c. una persona ven-/ vendía computadoras allá adelante $[. .$.$] fue$ a sacar dinero del banco/ y lo fueron siguiendo él/ inclusive $<$ inclusive:>/ di-/ le dijo a los de comerciantes de allá que lo venían siguiendo/ o sea porque vio [...] y se le hizo fácil bajarse $\mathrm{y}$ tratar de protegerse con los mismos/ tianguistas [...] mejor no se hubieran bajado porque ahí mismo lo mataron (comparación; entrevista 90; $12 \mathrm{H}$; turno 569).

d. yo quería ser bailarina [...] entonces $<\sim$ tons $>/$ ahorita con mi hija/ pues estoy así// fascinada/ aunque no la acompañe toda la vida/ ¿no?/ pero bueno [ya] [...] espero que sí [...] se vea/ este/ realizado ese sueño (concesión; entrevista 23; 32M; turno 20).

e. me ponía yo a lavar unas/ unas recámaras bien grandes como de aquí a hasta el zaguán/ de todo esto/ hasta el zaguán/ eran así unas recámaras/de puro a $<\sim a:>/$ duela de/ de madera/ quién sabe si usted las habrá conocido/ eran duela de madera/ y había que tallarlas/ bien/ que quedara la madera/ blanca/ para fin de que se pusieran/ se tenía que/ poner uno a/ a/ pintarlas/ de congo amarillo/ o de congo < congo: $>$ rosa o de/ de otros colores (consecución; entrevista 108; 13M; turno 47).

f. la verdad $<\sim$ verdá $>/$ pues $<\sim$ pus $>$ no/ no creo que haiga un hombre/ fiel/ la verdad < verdá $>$ / igual y/ y sí/ juntarme o casarme/ o lo que sea/ ¿no?/ pero pues < pus> más/ un poco más grande/ ya que/ realmente ya sepa lo que es juntarse// ¡la verdad $<\sim$ verdá $>$ ahorita $<\sim$ orita $>$ !/ no estoy preparada para un/ un matrimonio o algo así (creencia; entrevista $84 ; 11 \mathrm{M}$; turno 214).

g. para muchas gentes bueno resulta muy/ pues muy desdichado que te pinten el exterior de tu casa (evaluación; entrevista 30; $33 \mathrm{H}$; turno 81).

h. la policía no llega y [pregunta $<\sim$ pregunta:>] [...] quién fue y quién no fue sino < sino:> se hacen redadas y al que esté ahí lo agarran y se lo llevan (existencia; entrevista $78 ; 11 \mathrm{H}$; turno 78 ).

i. el < el::> administrador tuvo que entrar a la caja/ y le estaban pidiendo que abriera la caja/ y pues < pus> él no se sabía la 
combinación/ y lo estaban golpeando// dije/ "no/ pues < pus $>$ el cajero era para que/ abriera la caja y les diera el dinero/y que se vayan" (fin; entrevista 60; 22M; turno 261).

j. el < e:l> día que hubo la matanza de Tlatelolco [...] yo empecé a sentir como trabajo de parto y/ ya no ya no fui/ pero yo creo que si yo hubiera ido/ a lo mejor también me hubiera < biera $>$ tocado que me mataran (hipótesis; entrevista 72; 23M; turno 467).

k. Ecatepec estaba muy feo ahí antes [...] sí es- ahorita < orita: $>$ pues $<\sim$ pus $>$ no sé ya cuánto haya cambiado o que/ pues $<\sim$ pus $>$ si ya esté/ más tranquilo (incertidumbre; entrevista $78 ; 11 \mathrm{H}$; turno 784).

1. y pues bueno/voy con los hijos y todo/y pues andas a las vivas/ no te paras donde quieras $\mathrm{y} / / \mathrm{o}$ a veces andamos por ahí y ves que se orilla un coche y luego luego/ [te pones nervioso/ ¿no?] (locación; entrevista 50; 22H; turno 558).

m. fíjese que/ que tenía yo una comadre/ que le dije/ "comadre/ yo tengo mis/ mis padres/ pero < pus> la verdad no sé cómo/ cómo poder este/ encontrarlos" le digo/ ya tenía yo a mis hijos/ ya tenía yo a mi hijo el más chiquito/ "y yo no sé cómo encontrarlos comadrita" le decía yo/ este < este:> "yo quisiera/ pues saber/ de ellos (modalidad; entrevista 108; 13M; turno 41) ${ }^{10}$.

n. a mejor que escuela de la vida es la calle/ depende/ como la/ puedas tú/ digamos este < este: $>$ / vivir/ porque si tú te co-/ te tiras al vicio con perdón tuyo/ pues $<\sim$ pus $>$ ya no/ pero hay que saber (modo; entrevista 102; $13 \mathrm{H}$; turno 88 ).

o. tenía que cuando él llegara/ tenía que estar la comida servida [...] y si no/ pues < pus > eran golpizas que me daba/ donde me cayera (tiempo; entrevista 108; 13M; turno 62).

p. no fue un consejo/ o sea me dijo/ "no te estoy regañando/ ni no na- que/ no quiero que te juntes con mi sobrino/ ¿no?/ pero/ igual y piénsalo porque sí están muy chicos/ para echarse un compromiso así" (volición; entrevista 84; 11M; turno 846).

Otro aspecto que conviene incluir en la descripción del uso de las formas subjuntivas es la inserción o no inserción de éstas, en el ámbito de un operador

10 Se trata, como puede verse, de un caso de subjuntivo morfológico pero con valor objetivo (supra, equivalente a un pospretérito). 
negativo; los datos de frecuencia absoluta y relativa se presentan en el cuadro 7.

Cuadro 7. Presencia del operador negativo. $\mathrm{N}=1164$

\begin{tabular}{|l|c|c|}
\hline & $\mathrm{F}$ & $\mathrm{f}$ \\
\hline No está presente (ámbito afirmativo) & 853 & 0.733 \\
\hline Sí está presente (ámbito negativo) & 311 & 0.267 \\
\hline
\end{tabular}

Aunque se ha señalado la influencia de la negación en la presencia del subjuntivo, su aparición es relativamente minoritaria en nuestra base de datos, pues corresponde a poco más de uno de cada cuatro casos. (8a) es un ejemplo de ámbito afirmativo y ( 8 b) de ámbito negativo. Cabe resaltar que un número apreciable de contextos negativos corresponde a las formas de sentido imperativo del tipo no vengas o no creas, la mayoría de ellas instaladas, por otra parte, en proposiciones principales. Otro grupo interesante de ámbito negativo está asociado al sentido de incertidumbre, especialmente en subordinadas sustantivas con verbos de conocimiento, en construcciones del tipo no sé si lo sepa, cuyos subjuntivos son intercambiables por indicativos, quizá marcando por medio de estos últimos un mayor grado de asertividad (no sé si lo sabe).

a. le mandaban a uno ya el pedido// y < y: $>$ decían/ "no/ pues $<\sim$ pus $>$ está aceptado"/ entonces < entós> ya nomás era de andar al tanto/y dónde lo iban a entregar/ por ejemplo si le habíamos puesto que lo/ entregaran directamente por ejemplo a Chihuahua/ La Paz (ámbito afirmativo; entrevista 66; 23H; turno 318).

b. tenemos unos clientes que son/ pilotos aviadores los dos/ y eh/ apenas les arreglamos su terraza nosotros $[. .$.$] y pusimos cantidad$ de plantas y/ todo en macetas ieh?/ o sea no te creas que// que rellenamos de tierra ni mucho menos// todo todo con macetas (ámbito negativo; entrevista 50; 22H; turno 462).

Las dimensiones de factualidad, probabilidad y asertividad se describen en los tres cuadros siguientes.

Cuadro 8. Distribución de la factualidad. N=1164

\begin{tabular}{|l|c|c|}
\hline & F & f \\
\hline No es factual & 980 & 0.842 \\
\hline Sí es factual & 184 & 0.158 \\
\hline
\end{tabular}


La ausencia de factualidad está asociada al carácter irrealis del subjuntivo, por lo que es de esperar que sea el valor predominante. La expectativa se cumple, de hecho, en la mayor parte de los casos (aproximadamente en el $85 \%$, como en 9a). Sin embargo, resulta especialmente interesante encontrar ejemplos donde el contexto revela de manera inequívoca el carácter factual del ejemplo, y que de todas maneras se presentan en subjuntivo. Es lo que ocurre en (9b), donde se dice para que sucediera todo lo que pasó, de forma que todo lo que pasó no deja ninguna duda del cumplimiento del evento y cancela la posibilidad de que no hubiera sucedido. En este tipo de casos, parece que los condicionamientos sintácticos -se trata de una subordinada adverbial final- condicionan el surgimiento del subjuntivo, sin dejar resquicio a la aparición del indicativo.

a. Actipan [...] era bien bonito porque/ bueno/ como que vivías en un pueblo// no había/ pavimento/ no había/ a lo mejor ni luz/ yo no me acuerdo que hubiera luz// digo en la calle/ ¿no?// había unos arbolotes gigantescos/ que nada más queda como uno o dos ahí en/ en el barrio (no factual; entrevista 50; 22H; turno 209).

b. fui a levantar la demanda/ y ahí me dieron mi regañiza/ me dijeron// "si usted tuvo la oportunidad de salirse/ lo hubiera hecho/ usted no tenía por qué haber salido y ponerse ahí para que// la vieran y < y:>sucediera todo lo que pasó"/ ¿no? (factual; entrevista 60; 22M; turno 228).

La probabilidad de que la acción se lleve a cabo es otro parámetro interesante a la hora de establecer los usos del subjuntivo, aunque hay que decir que existe un amplio margen de incertidumbre a la hora de asignar la interpretación en el proceso de análisis ${ }^{11}$.

11 García Fajardo señala, a propósito del pretérito de subjuntivo, que los verba dicendi proporcionan al sujeto de la principal de un rasgo de involucramiento con el evento de la subordinada, como en María dijo que Susana preparara la comida; otro tanto corre con evidenciales como ver o escuchar (Juan vio que el vigilante cerrara la puerta). El involucramiento se proyecta sobre una escala dotada de tres grados: evidencia indirecta, evidencia sensorial y corresponsabilidad, en sus términos (2001: 103-105). 
Cuadro 9. Distribución de la probabilidad. $\mathrm{N}=1164$

\begin{tabular}{|l|c|c|}
\hline & $\mathrm{F}$ & $\mathrm{f}$ \\
\hline Acción de realización improbable & 784 & 0.674 \\
\hline Acción de realización probable & 380 & 0.326 \\
\hline
\end{tabular}

Hemos marcado como de cumplimiento probable aproximadamente la tercera parte de los casos. En general, uno de los principales subconjuntos de subjuntivos probables son todos o casi todos los casos de carácter factual, donde la asignación de probabilidad es hasta cierto punto trivial. Otro grupo interesante de realización probable son ejemplos de presentes de subjuntivo que permiten una interpretación de futuridad, como ocurre en el ejemplo (10b), donde la resolución de la acción en un momento posterior es permitida por la forma escarbe. Por otro lado, es claro también que el contexto es determinante en la interpretación de la probabilidad: obsérvese la presencia del presente de indicativo en la especie de apódosis final, parafraseable como si escarbas, encuentras piedra. La relativa probabilidad del cumplimiento de la acción está también relacionada con la intercambiabilidad por el indicativo, especialmente en las prótasis y apódosis de condicionales, como en si vinieras, te cansarías, frente a si venías, te cansabas, aunque el cambio de modo provoca algunas diferencias de significado, como se comenta más adelante.

a. o luego ve por ejemplo una chamaquita de la secundaria con novio ¿no? (ruidos) así abrazándose y besándose "nada más que te vea yo así me las vas a pagar" dice "ay papá como si ya me estuvieras viendo/ te digo mamá ve a mi papá"/ le digo "ay no le hagas caso" (improbable; entrevista 96; 12M; turno 555).

b. en el Ajusco/ pues < pus> la ciudad de México está construida sobre/ mh tie- piedra volcánica/ ¿no? [...] [y esa es una] mina que no se acaba/ o sea// cualquiera que escarbe allá en la zona donde estamos/ encuentras piedra (probable; entrevista 50;22H; turno 321).

Muy pocos de los subjuntivos están asociados al carácter asertivo ${ }^{12}$, como se muestra en el cuadro 10 .

12 Tomamos asertivo en el sentido tradicional en la teoría de actos de habla. Si los actos de habla representativos establecen en general lo que el hablante cree que son o no las cosas, 
Cuadro 10. Distribución de la asertividad. $\mathrm{N}=1164$

\begin{tabular}{|l|r|c|}
\hline & \multicolumn{1}{|c|}{ F } & f \\
\hline Sin carácter asertivo & 1128 & 0.969 \\
\hline Con carácter asertivo & 36 & 0.031 \\
\hline
\end{tabular}

La razón de esta baja frecuencia parece tener que ver con el hecho de que el indicativo es el modo de la asertividad (es decir, de la afirmación de una proposición). Los casos de intercambiabilidad de modo con escasos cambios de significado tienen que ver, precisamente, con la asertividad ganada al emplazar en el contexto el indicativo. Por otro lado, los escasos subjuntivos que hemos etiquetado como asertivos suelen llevar marcas explícitas en el contexto que permiten el surgimiento de la asertividad. Tal es lo que ocurre en (11b), donde el sí en sí te dé su lugar parece aportar el bagaje necesario para caracterizar la cláusula como asertiva. Piénsese en la diferencia entre pero que venga y pero que sí venga. Cabe discutir, por otro lado, que la asertividad no es aportada por el subjuntivo mismo, sino por el contexto proposicional; esto es cierto, pero de alguna manera confirma la necesidad de interpretar el valor de los subjuntivos en contextos de uso específicos, y no en términos puramente abstractos ${ }^{13}$.

a. son como [líderes o músicos/ bailarines] [...] nunca he tenido/ algo que no tenga que ver con la música (no especialmente asertivo; entrevista $48 ; 21 \mathrm{M}$; turno 419 ).

b. igual y ahorita $<\sim$ oríta $>$ yo digo/ "es que ninguno es fiel"/ pero igual y me encuentro a alguien/ ¿no?/ o sea que no sea realmente fiel/o sea porque nunca nadie va a ser realmente fiel pero/ digo igual y sí te dé tu lugar y cosas así/ ¿no? (con cierto carácter asertivo; entrevista $84 ; 11 \mathrm{M}$; turno 629 ).

haciendo que las palabras se ajusten al mundo, o la creencia acerca del mundo, el subtipo asertivo asienta la afirmación vigorosa o compromiso del hablante con la realidad representada (cf. Yule 2011: 53).

13 Además, como puede apreciarse en pero que sí venga, algunos ejemplos no son asertivos representativos puros, sino asertivos vinculados a actos de habla directivos. Véase también el caso de (11b), no exento de rasgos comisivos, más allá de la relativa asertividad con que se formula. 
Uno de los aspectos más importantes que hay que considerar tiene que ver con la posible intercambiabilidad del subjuntivo con el indicativo. Siguiendo en este punto muy de cerca la propuesta de Silva-Corvalán (1994: 260 y ss.), caben cuatro posibilidades: que el subjuntivo sea obligatorio; que sí sea intercambiable, pero que la presencia del indicativo desate diferencias semántico-pragmáticas claras; que estas diferencias sean sólo medianas; o que sólo descansen en la subjetividad del hablante. El cuadro 11 resume los datos presentes en el corpus examinado.

Cuadro 11. Distribución de la intercambiabilidad con el indicativo. $\mathrm{N}=$ 1164

\begin{tabular}{|l|r|r|r|r|}
\hline & \multicolumn{1}{|c|}{$\mathrm{F}$} & $\mathrm{f}$ & $\mathrm{F}$ (no/sí) & $\mathrm{f}$ (no/sí) \\
\hline No es intercambiable & 725 & & 725 & 0.623 \\
\hline Intercambiable con diferencias claras & 211 & 0.181 & \multirow{2}{*}{439} & 0.377 \\
\cline { 1 - 3 } Intercambiable con diferencias medianas & 30 & 0.026 & & \\
\cline { 1 - 3 } $\begin{array}{l}\text { Intercambiable con diferencias subjetivas } \\
\text { o sin diferencias }\end{array}$ & 198 & 0.170 & & \\
\hline
\end{tabular}

Un poco menos de las dos terceras partes de los casos corresponden a ejemplos en los que el uso del subjuntivo es completamente obligatorio, como ocurre en (12a) y en (12b), donde la presencia del tiempo correspondiente de indicativo parece desembocar en resultados agramaticales: *Me gustaría que no habia hombres mujeriegos; *Me gustaría que no habría hombres mujeriegos; *Tenía yo que hacerlos que hacían las cosas; *Tenía yo que hacerlos que harían las cosas. En nuestros materiales, los valores que más piden el subjuntivo son las construcciones causativas, comparativas, consecutivas, finales y volitivas, que salvo contadas excepciones se desarrollan obligatoriamente con subjuntivo. Quedan a medio camino las construcciones causales, concesivas, de creencia, evaluativas, existenciales, hipotéticas, temporales y de modo. Por fin, casi siempre son de subjuntivo intercambiable las de incertidumbre, las locativas y las modales.

La intercambiabilidad con diferencias claras suele estar ligada al carácter factual o no del evento. Así, en (12c), la diferencia básica entre cuando te pase y un posible cuando te pasa, es la realización efectiva cuando se emplea el indicativo. En cuanto al contexto sintáctico, solo las subordinadas adjetivas favorecen con cierta notoriedad el intercambio con diferenciación clara (más o menos en uno de cada tres casos, 65 de 176); en un nivel medio se encontrarían las adverbiales (poco más de uno de cada cinco casos) y las sustantivas (una de cada siete veces); muy lejos quedan ya los demás tipos sintácticos. Desde el punto de vista de los valores semánticos, llama 
la atención la relativa prominencia de las construcciones concesivas (19 casos), las de creencia (13 casos), las existenciales (99) y las temporales $(19)^{14}$.

La intercambiabilidad con diferencias medianas aparece en buena medida ligada a la probabilidad de que el evento se lleve a cabo. La mayor parte de los casos se concentra en las prótasis de las condicionales ${ }^{15}$, como en (12d), de manera que se pondera así el cambio de significado entre Si me pusiera a contar más yo creo que se me borra la cinta y Si me ponía a contar más yo creo que se me borra la cinta. También hemos marcado diferencias medianas en algunos casos de apódosis y en algunas adverbiales concesivas y causales. Ciertamente, esta distinción intermedia en cuanto al cambio de significado es discutible en más de un caso, y es posible que sea más productivo reducir la escala de casos intercambiables a solo dos niveles, de diferencias claras frente a diferencias menudas.

Por fin, hubo casi 200 casos atribuibles a diferencias en el grado de asertividad que se marca con el subjuntivo frente al que podría marcarse con el indicativo ${ }^{16}$, o bien sin ninguna diferencia apreciable entre la forma de subjuntivo y el condicional correspondiente. Se trata, en el primer caso, de pares como los formulables entre ¿No sé si los conozcas? (12e) y ¿No sé si los conoces? y, en el segundo, de ejemplos como Hubiera sido más sencillo para mí (12f) y Habría sido más sencillo para mí. Los ejemplos del tipo (12e) son particularmente interesantes por su recurrencia en los datos mexicanos. Cabe realizar alrededor de ellos dos posibles interpretaciones. La primera, que la baja asertividad esté relacionada con la atenuación pragmática en la interacción conversacional (hecho ya señalado a propósito de otros fenómenos, como los diminutivos, las formas de tratamiento y las peticiones). Una segunda posibilidad es que -aun cuando existiera en origen o en ciertos casos específicos un residuo de este valor atenuador- se haya perdido en buena parte de los ejemplos el valor [-asertivo], de forma que solo estaríamos frente a un marcador dialectal ${ }^{17}$.

14 Silva-Corvalán ejemplifica las diferencias significativas claras con las proposiciones adjetivas y las adverbiales de modo, tiempo, lugar, etc. Como puede apreciarse, nuestros resultados son solo parcialmente coincidentes con tal perspectiva.

15 En coincidencia con Silva-Corvalán (1994: 260 y ss.).

16 Silva-Corvalán (1994, p. 260 y ss.) habla de diferencias semántico-pragmáticas subjetivas por parte del hablante, que en última instancia parecen deslindarse a través de un rasgo [ \pm asertivo].

17 Convendrá explorar estas posibilidades en más detalle en otro trabajo, donde cobren mayor importancia los valores discursivos de las formas supuestamente atenuadas. 
(12)

a. ¿cómo me gustaría?/ pues $<\sim$ pus $>$ igual que no hubiera hombres mujeriegos (no intercambiable; entrevista $84 ; 11 \mathrm{M}$; turno 210).

b. yo que crié tres hijos/ se puede decir que tres hijos porque/ el/ el tercero/// el cuarto/ y el quinto [...] yo era hombre y mujer/ que tenía yo que/ que/ hacerlos que hicieran las cosas/ y que " ¿sabes qué? que necesito que me hagas esto// pero ya// a la de ya/ porque todos esta- trabajamos aquí y todos tenemos que/ que compartir las cosas" (no intercambiable; entrevista 108; 13M; turno 226).

c. luego mi hijo está como < como: $>$ / como que le quiero decir y como que no ¿no?/ entonces mi esposo dice/ "ay no tú cuando te pase algo hijo/ ya te dice ya te dije que sea lo que sea/ tú me tienes que decir sea bueno o sea malo lo que/ tú no debes de quedarte callado/ y ya sab-/ ya vamos a ver cómo arreglamos eso" (intercambiable con diferencias claras; entrevista 96; 12M; turno 551).

d. si < si: $>/$ me pusiera a contar más/ yo creo que/ se me borra la cinta pero/ no sé si vaya muy parejito (intercambiable con diferencias medianas; entrevista $66 ; 23 \mathrm{H}$; turno 538 ).

e. yo tenía un perro que/ de raza setter < séter $>$ irlandés/ ¿no sé si los conozcas?/ rojos (intercambiable con diferencias subjetivas; entrevista 50; $22 \mathrm{H}$; turno 526).

f. si él no hubiera tenido ningún compromiso/ hubiera sido más sencillo para mí (intercambiable sin diferencias; entrevista 23; 32M; turno 349).

También se registra un cierto número de casos de posibles alternancias con el infinitivo, del tipo de las presentadas en (13):

a. tú le puedes decir a mi mamá/ "¿sabes qué mamá?/ mira/ no es necesario que hagas la casa// totalmente/ sino que"/ ¡ah/ no!/ pero es una persona que/ si todos los días tiene que hacer la casa (entrevista $6 ; 31 \mathrm{H}$; turno 98).

b. tenía que cuando él llegara/ tenía que estar la comida servida $[\ldots]$ y si no/ pues < pus $>$ eran golpizas que me daba/ donde me cayera/// entonces este/ pues rápido vete a lavar $\mathrm{y} / \mathrm{y}$ regresas para que hagas la comida porque tu marido va a llegar y/y necesita de comer (entrevista 108; 13M; turno 62). 
Es decir, (13a) podría haberse expresado como No es necesario hacer la casa totalmente, y (13b) como Regresas para hacer la comida porque tu marido va a llegar. Aunque el número de casos con alternancia posible no es muy elevado, el análisis sintáctico y pragmático de los resultados precisará de un trabajo aparte.

Puede decirse que no hubo casos inadecuados propiamente dichos. Hubo, sin embargo, algunos datos que producen cierta extrañeza; entre ellos se cuentan los siguientes:

a. no toda la planta que nosotros utilizamos en/ en/ en el trabajo/ la producimos/ o la produzca mi suegro (entrevista $50 ; 22 \mathrm{H}$; turno 420).

b. la otra entrada que sigue/ de donde yo entraba este/ ahora hay unos cuatrimotos $\mathrm{y} /$ restoranes y[...] igual y llegas al río/ yo creo que sí todavía exista pero/ pero pues ya es bien diferente (entrevista $50 ; 22 \mathrm{H}$; turno 556).

c. si me hubiera yo < yo:> esperado [...] los cuatro años/ me hubieran este/ evaluado los demás [...] si yo le hubiera buscado la manera/y entonces mi pensión no estuviera tan raquítica [...] hubiera sido jubilación completa/ a los treinta años (entrevista 66 ; $23 \mathrm{H}$; turno 346).

d. pues de/ mi mamá ahorita bueno tuviera yo otra hermana/ que tuviera< tuviera: $>$ / un año más que yo/ pero falleció/ ella chiquita (entrevista 96; 12M; turno 105).

e. [ahorita] más o menos tuviera mi hermano como < como: $>/$ cuarenta y $\langle\sim \mathrm{y}:>/$ ocho o cuarenta y nueve/ años (entrevista 96; 12M; turno 125).

f. me dijo "porque como es muy reciente su $<\sim$ su: $>/$ embarazo/ se la vaya a abrir la he- los tejidos" (entrevista 96; 12M; turno 329).

g. llega tu esposo "ay ¿cómo te fue?"/ "no pues $<\sim$ pus $>$ fijate que me fue bien" o "fijate que me pasó esto ¿no?"/ o sea ya tienes con quien platicar/ entonces los hijos/ o sea con los hijos no es lo mino viene siendo lo mismo porque/ sí tienes la confianza con ellos pero/ no es mejor que/ este tener tu pareja/ porque imagínate si fueras madre ponle soltera $\mathrm{o}$ / madre separada no fuera lo mismo (entrevista 96; 12M; turno 515).

h. pues $<\sim$ pus $>$ yo digo que sí porque si no ya/ desde cuándo ya estuviéramos separados (entrevista 96; 12M; turno 537). 
i. yo creo que mi papá le ha dado/ pues < p pus $>$ buen apoyo/ y todo $<\sim$ to $>$ eso siempre/ y no haya necesitado de s-/ de su familia (entrevista $6 ; 31 \mathrm{H}$; turno 64).

En el caso (14a), no es fácil explicar la aparición del subjuntivo, especialmente porque aparece en disyunción con un indicativo; habría que suponer una paráfrasis del tipo de no toda la planta la producimos o quepa decir que la produzca mi suegro, con un subjuntivo dotado además de bajo valor asertivo, pues sería incluso en ese contexto forzado intercambiable por un indicativo. El ejemplo (14b) parece ser relativamente común en México, de modo que en él el valor atenuador asociable a la baja asertividad del subjuntivo parece predominar sobre la asertividad promovida por el sí. El caso de (14c) parecería pedir un antepretérito, de manera que hubiera estado, en vez de estuviera, correspondería, además, a las formas hubiera buscado y hubiera sido, presentes en el contexto inmediato. Los ejemplos (14d, e, g, h) presentan subjuntivos donde cabría esperar una forma condicional, del tipo no sería lo mismo, en vez de no fuera lo mismo; todos ellos proceden de la misma informante. También de ella es el caso (14f), donde parece faltar, quizá por razones discursivas, un operador negativo, que justificaría el subjuntivo: no se le vaya a abrir la herida. Por último, el ejemplo (14i) parece haber nacido de una elipsis discursiva, quizá parafraseable como le ha dado buen apoyo y todo eso siempre y eso explica que no haya necesitado...

Fuera de estos casos, en buena medida explicables por cuestiones discursivas -y otros asociados a una misma persona-, la enorme mayoría de los ejemplos, no presenta problemas de adecuación, lo que era, en realidad, esperable dada la vitalidad del subjuntivo en la ciudad de México.

A continuación, se examina el papel de los factores sociales.

\section{FACTORES SOCIALES}

El examen de la dimensión social de las formas subjuntivas revela algunos detalles interesantes. En primer término, es necesario separar, en el total de los datos, las personas que los produjeron, de modo que el cruce con las variables sociales se lleve a cabo estrictamente con los ejemplos producidos por los informantes (véase el cuadro 12). 
Cuadro 12. Procedencia de los datos. $\mathrm{N}=1164$

\begin{tabular}{|l|r|c|}
\hline & \multicolumn{1}{|c|}{ F } & f \\
\hline Informante & 1029 & 0.884 \\
\hline Otro participante & 1 & 0.001 \\
\hline Entrevistador & 132 & 0.113 \\
\hline Co-entrevistador & 2 & 0.002 \\
\hline
\end{tabular}

Como puede apreciarse, la inmensa mayoría de los datos (más del $88 \%$ ) fue producida por los informantes (como por ejemplo en 15a). En segundo lugar, los entrevistadores documentaron un número no tan pequeño de ejemplos (ligeramente más del 11\%, como en $15 \mathrm{c}$ ), generalmente a través de turnos de habla breves o relativamente breves. Por último, de manera casi marginal hubo un solo ejemplo de otro participante en la entrevista (es el incluido en $15 \mathrm{~b}$ ) y un par de casos producidos por un co-entrevistador, es decir, alguien que acompañaba o apoyaba al entrevistador propiamente dicho (uno de los dos ejemplos es el que se copia en 15d). El resto de las consideraciones sociales se lleva a cabo solo con los 1029 ejemplos surgidos en turnos de habla de informantes.

a. yo tenía que darle de comer a mis hijos porque es/ ni modo que los tuviera sin comer/ entonces yo tenía yo que trabajar/ de lava $<\sim$ lava:> trastes/ de/ haciendo quehacer (informante; entrevista 108; 13M; turno 47).

b. ojalá nos tocara (otro participante; entrevista 50; turno 489).

c. ¿por donde vives es común/ que los dos trabajen?/ o sí/ ¿la chava sí se queda? (entrevistador; entrevista 84; turno 247).

d. pero lo bueno de usted es que/ aunque haya subido de puesto/ se acordaba de/ bueno/ seguía haciendo también las labores que/ seguía haciendo (co-entrevistador; entrevista 60; turno 430).

El cuadro 13 expone los resultados según el nivel de estudio, bajo, medio o alto, de los 18 informantes considerados. Aunque las diferencias son mínimas entre las personas de nivel medio y de nivel alto, que documentaron alrededor de $36 \%$ y $35 \%$ de los datos, respectivamente, parece existir un poco más de distancia con respecto a las personas de nivel bajo (30\%): 
Cuadro 13. Distribución según el nivel de estudios de los informantes. N= 1029

\begin{tabular}{|l|c|c|}
\hline & $\mathrm{F}$ & $\mathrm{f}$ \\
\hline Nivel bajo (grupo 1) & 305 & 0.296 \\
\hline Nivel medio (grupo 2) & 367 & 0.357 \\
\hline Nivel alto (grupo 3) & 357 & 0.347 \\
\hline
\end{tabular}

De esta manera, (16a, b y c) son ejemplos representativos de cada uno de estos tres niveles de estudios. Hay que decir, por otra parte, que aunque las diferencias van más o menos en la dirección que pudiera esperarse, son en realidad bastante pequeñas y no parecen marcar diferencias serias entre ninguno de los niveles, lo cual habla, en última instancia, de la vitalidad del subjuntivo en el conjunto de la comunidad. Estos hallazgos son muy diferentes, por ejemplo, a los resultados expuestos por Silva-Corvalán para Los Ángeles, quien muestra un descenso gradual en el uso del subjuntivo en tres grupos de hablantes: $42.4 \%$ (376 de 886 casos) entre los inmigrantes nacidos en México y llegados a Estados Unidos con más de 11 años; 26.5\% (225 de 849) entre los hablantes nacidos en Los Ángeles de padres nacidos en México; y 17.3\% (171 de 986 ejemplos) entre las personas nacidas en Los Ángeles con al menos uno de sus padres también nacidos en la misma ciudad (1994: 256 y 265).De todos modos, será necesario llevar a cabo un análisis específico de los usos que se documentan en mayor o menor abundancia en cada uno de los grupos sociales; por ejemplo, podría esperarse que el llamado por Hummel subjuntivo retórico (cf. 2004, cap. 9; y 2005 para datos chilenos orales), derivado de usos cultos y escritos, asociado a una sintaxis compleja, aparezca poco en los grupos menos instruidos, pero tal extremo va más allá de los límites de esta aproximación.

a. la verdad $<\sim$ verdá $>/$ pues $<\sim$ pus $>$ no/ no creo que haiga un hombre/ fiel/ la verdad < verdá>/ igual y/ y sí/ juntarme o casarme/ o lo que sea/ ¿no?/ pero pues < pus> más/ un poco más grande/ ya que/ realmente ya sepa lo que es juntarse// ¡la verdad < verdá $>$ ahorita $<\sim$ orita $>$ ! no estoy preparada para un/ un matrimonio o algo así (nivel bajo; entrevista $84 ; 11 \mathrm{M}$; turno 214).

b. a veces te toca la noche y te tienes que dormir en tu camión/ y ni modos (sic)// salvo cuando llegas a alguna ciudad así donde/ hay que ir a descargar/ o hay que esperar carga/ este pues $<\sim$ pus $>$ bueno/ se puede uno hospedar en un hotel o algo [...] pero de ahí 
en fuera/ pues es/ cosa de dormir en/ en donde se pueda (nivel medio; entrevista 50; 22H; turno 81).

c. es política// la fatuidad/ la presunción/ el fariseísmo de todos ellos/ contradicen en mucho/ los principios// etéreos/ los principios/ eh/ ¿cómo te dijera?/ profundos/ oscuros y secretos// no transmisibles/ que debe tener/ una religión (nivel alto; entrevista 30; 33H; turno 584).

Precisamente los resultados vinculados a la distribución por edades confirman la perspectiva general de una amplia vitalidad en el uso del subjuntivo a partir de los datos del Corpus sociolingüistico de la ciudad de México (cuadro 14).

Cuadro 14. Distribución según la edad de los informantes. N=1029

\begin{tabular}{|l|c|c|}
\hline & F & f \\
\hline Edad 1 (20-34 años) & 409 & 0.397 \\
\hline Edad 2 (35-54) & 350 & 0.340 \\
\hline Edad 3 (55-) & 270 & 0.262 \\
\hline
\end{tabular}

Llama la atención, en efecto, que cuanto menor es la edad de los informantes, mayor es la proporción en el uso de formas subjuntivas. Si las personas de más edad concentraron apenas el $26 \%$ de los datos, la proporción asciende al $34 \%$ entre los informantes de edad mediana y a casi al $40 \%$ entre los jóvenes. Aunque parecería demasiado aventurado atribuir tales cantidades a algún tipo de cambio lingüístico, y para ello haría falta un examen mucho más detenido de los datos, nos parece que estas cantidades subrayan claramente la plena vitalidad del subjuntivo en los datos mexicanos, por lo menos vistos en términos globales. En la serie incluida en (17) se anotan algunos ejemplos ilustrativos de cada uno de los grupos etarios.

a. si hago este curso/ dura tres años el curso para que/ en donde te preparan/ para que tú hagas un examen/ en Estados Unidos/ en Canadá/ en Europa/ o en donde quieras// haces ese examen y si lo pasas// ya te certifican en donde tú quieras como médico/ no importa que sea de aquí de México/ no importa/ ya te vas como un médico/ y puedes ejercer allá lo que tú quieras (edad 1 ; entrevista 12 ; $31 \mathrm{M}$; turno 175 ).

b. la tele pues/realmente muy ocasionalmente/ prefiero/ hacer otras cosas que/ que ver la tele/ digo/ no quiero decir con esto que no 
lo haga/ o sea sí lo llego a/ hacer/ pero [...] pero no es así como/ mi esposo (edad 2; entrevista 23; 32M; turno 34).

c. que ellos realmente digan/"hice el mejor esfuerzo/y mis asesores también hicieron mi mejor esfuerzo"/ y de vez en cuando por lo menos digan/ "no/ pues a mí me enseñó a multiplicar de esta manera o/ divido de esta manera/ porque así me enseñó mi maestro en la [nocturna"] [...] a que digan/ "no pues $<\sim$ pus $>$ ahí ni siquiera nos enseñaron/ ni cómo se hacía" (edad 3; entrevista 72; 23M; turno 1037).

Por fin, otro factor que llama la atención es la distribución del subjuntivo según el género de los informantes, pues existe una diferencia de cierta envergadura entre hombres y mujeres (cuadro 15).

Cuadro 15. Distribución según el género de los informantes. N=1029

\begin{tabular}{|l|c|c|}
\hline & F & f \\
\hline Hombres & 458 & 0.445 \\
\hline Mujeres & 571 & 0.555 \\
\hline
\end{tabular}

Las mujeres, de hecho, presentan un porcentaje superior al de los hombres en más o menos diez puntos; pueden verse los correspondientes ejemplos en (18a) y (18b), para hombres y mujeres, respectivamente. De alguna manera, estos resultados -que sin duda necesitan explorarse en más detalle-concuerdan con la idea general de que las mujeres suelen mostrar un mayor grado de riqueza discursiva cuando menos en las situaciones de entrevista.

a. ganamos muchas medallas y/y sí me fue muy bien en ese grupo/ yo ahí/ no me hubiera salido hasta que me querían enclaustrar ya en el colegio (hombre; entrevista 42; 21H; turno 104).

b. llegué a Mamá Rumba un día y/ y el que arma el show de ahí me dijo "oye quiero que/ sean cuatro cubanas y hagan figurante/ pero necesito niñas cubanas" [...] "porque va a venir el Ban-bán/ y quiero que lo reciban puras chavas este/ cubanas" (mujer; entrevista 48; 21M; turno 125). 


\section{CONCLUSIONES}

Las principales conclusiones que cabe establecer a partir de esta aproximación al uso de las formas subjuntivas en el Corpus sociolingüístico de la ciudad de México son las siguientes:

1. El subjuntivo presenta, visto al menos de manera global, una vitalidad plena en la ciudad de México, como era de esperarse.

2. Las formas más comunes son el presente y el pretérito, pero no faltan, en la lengua hablada, casos de antepresente y antepretérito. Los contextos sintácticos y los valores semánticos y enunciativos son importantes para caraterizar el uso del subjuntivo, pero, para expresar la alternancia con el indicativo, es importante acudir a valores como la factualidad, la probabilidad y la asertividad puestas en juego en cada ejemplo específico.

3. En cuanto a las variables sociales, existen ciertas asociaciones que merece la pena explorar en más detalle: un cierto mayor uso entre las personas con más estudios, entre los informantes más jóvenes y entre las mujeres.

4. Es necesario profundizar en las funciones, usos y orígenes históricos específicos de los 439 casos en que existe cierto grado de intercambiabilidad entre indicativo y subjuntivo.

\section{REFERENCIAS BIBLIOGRÁFICAS}

Bello, ANDrés. 1981. Gramática de la lengua castellana destinada al uso de los americanos. Ed. R. Trujillo. Santa Cruz de Tenerife: Instituto Universitario de Lingüística Andrés Bello - Cabildo Insular de Tenerife.

Blas Arroyo, José Luis. 2005. Sociolingüística del español. Desarrollos y perspectivas en el estudio de la lengua española en contexto social. Madrid: Cátedra.

Bosque, Ignacio. 1990. Las bases gramaticales de la alternancia modal. Repaso y balance. En Indicativo y subjuntivo, pp. 13-65. Madrid: Taurus.

Busch, HANS-JöRg. 2009. La enseñanza del subjuntivo en EE.UU. El subjuntivo en cláusulas nominales. Revista de Lingüistica Teórica y Aplicada 47: 145-166.

DeMello, George. 1996. Indicativo por subjuntivo en cláusula regida por expresión de reacción personal. Nueva Revista de Filología Hispánica 44: 365-386.

Escandell Vidal, M. Victoria. 1993. Introducción a la pragmática. Barcelona: Anthropos Madrid: Universidad Nacional de Educación a Distancia.

Hummel, Martin. 2004. El valor básico del subjuntivo español y románico. Cáceres: Universidad de Extremadura. 
2005. Zum Gebrauch des Konjunktivs im gesprochenen Spanisch Chiles. En Volker Noll y Haralambos Symeonidis (eds.). Sprache in Iberoamerika. Festschrift für Wolf Dietrich zum 65 Geburtstag, pp. 313-339. Hamburgo: Helmut Buske.

Knauer, Gabriele. 1998. Der subjuntivo im Spanischen Mexikos. Tübingen: Niemeyer.

García Fajardo, Josefina. 2001. El pretérito de subjuntivo: suspensión de la aserción y modalidad. En Semántica. Oración y enunciación, pp. 95-113. México: El Colegio de México.

Lastra, Yolanda y Pedro Martín Butragueño. 2010. Futuro morfológico y futuro perifrástico en el Corpus sociolingüistico de la ciudad de México. Oralia 13: 145-171.

Lavandera, Beatriz. 1984. Variación y significado. Buenos Aires: Hachette.

LÁzaro Carreter, Fernando. 1981. El mensaje literal. En Estudios de lingüistica, pp. 149171. Barcelona: Crítica.

Moreno de Alba, José G. 2003a. Frecuencias de las formas verbales en el español hablado en México. En Estudios sobre los tiempos verbales, pp. 25-42. México: Universidad Nacional Autónoma de México.

2003b. Algunas concurrencias entre el infinitivo y el subjuntivo en la hipotaxis del español hablado en México. En Estudios sobre los tiempos verbales, pp. 89-99. México: Universidad Nacional Autónoma de México.

Real Academia Española - Asociación de Academias de la Lengua Española. 2009. Nueva gramática de la lengua española. Madrid: Espasa.

Ridruejo, Emilio. 1999. Modo y modalidad. El modo en las subordinadas sustantivas. En Ignacio Bosque y Violeta Demonte (eds.). Gramática descriptiva de la lengua española, vol. 2, pp. 3209-3251. Madrid: Espasa Calpe.

Rivero, Ma. Luisa. 1990. Especificidad y existencia. En Ignacio Bosque (ed.). Indicativo y subjuntivo, pp. 261-279. Madrid: Taurus.

Silva-Corvalán, Carmen. 1994. The gradual loss of mood distinctions in Los Angeles Spanish. Language Variation and Change 6: 255-272.

2001. La variable indicativo-subjuntivo. En Sociolingüística y pragmática del español, pp. 138-154. Washington: Georgetown University Press.

Studerus, Lenard. 1995. Some unresolved issues in Spanish mood use. Hispania 78: 94-104.

Vázquez Laslop, María Eugenia. 2007. Pudiera de dicto. Nueva Revista de Filología Hispánica 55: 1-22.

VeIGA, AleXANDRE. 2006. Las formas verbales subjuntivas. Su reorganización modo-temporal. En Concepción Company (dir.). Sintaxis histórica de la lengua española. Primera parte: la frase verbal, pp. 93-240. México: Universidad Nacional Autónoma de México - Fondo de Cultura Económica.

Yule, George. 2011. Pragmatics. Oxford: Oxford University Press. 